Research Article

\title{
Negative Surface Energies of Nickel Ferrite Nanoparticles under Hydrothermal Conditions
}

\author{
Zs. Rák $(\mathbb{D})$ and D. W. Brenner \\ Department of Materials Science and Engineering, North Carolina State University, Raleigh, NC 27695, USA \\ Correspondence should be addressed to Zs. Rák; zrak@ncsu.edu
}

Received 31 January 2019; Revised 30 August 2019; Accepted 9 September 2019; Published 7 October 2019

Guest Editor: Zhen Yu

Copyright (c) 2019 Zs. Rák and D. W. Brenner. This is an open access article distributed under the Creative Commons Attribution License, which permits unrestricted use, distribution, and reproduction in any medium, provided the original work is properly cited.

\begin{abstract}
The formation of nickel ferrite $\left(\mathrm{NiFe}_{2} \mathrm{O}_{4}\right)$ nanoparticles under hydrothermal conditions has been modeled using a method that combines results of first-principle calculations, elements of aqueous thermochemistry, and experimental free energies of formation. The calculations predict negative formation energies for the (111) surfaces and positive free energies for the formation of bulk nickel ferrite. Based on classical nucleation theory, the combination of the negative surface and positive bulk energies yields thermodynamically stable nickel ferrite nanoparticles with sizes between 30 and $150 \mathrm{~nm}$ in the temperature range of 300 to $400 \mathrm{~K}$ under alkaline conditions. The surface and bulk energetics as well as the stability of the nickel ferrite nanoparticle as a function of temperature and $\mathrm{pH}$ are discussed.
\end{abstract}

\section{Introduction}

Nanostructured materials can display physical properties that are very different from what they exhibit on the macroscale. This is because at nanoscale quantum effects become dominant, affecting the electrical, optical, and magnetic behavior of matter [1]. Furthermore, the reduction in particle size leads to a larger relative surface area, and this can alter the chemical reactivity and strength of the material. These characteristics make nanostructured materials to be of great scientific and technological interests [1-3]. Among nanostructured materials, magnetic nanoparticles have been the focus of intense research because of their potential use in numerous technological areas, for example, in catalysis, data storage, nanofluids, microwave devices, and defect sensors [4-8]. Nanosized nickel ferrite $\left(\mathrm{NiFe}_{2} \mathrm{O}_{4}\right)$ has received considerable scientific attention due to its magnetic characteristics that depend sensitively on the size, shape, purity, and thermal history of the samples $[9,10]$. Nickel ferrite nanoparticles have been synthesized through conventional techniques including solid-state reaction, sol-gel combustion, coprecipitation, and hydrothermal methods [9-17]. Among these methods, hydrothermal synthesis appears to be a promising technique to produce highly crystallized, weekly agglomerated powder, where particle size, morphology, and other characteristics can be controlled by adjustment of temperature, time, and $\mathrm{pH}$ value $[18,19]$.

Nickel ferrite is known to be present in the coolant of pressurized water reactors (PWR), and it is also a major component in the porous oxide deposits that accumulate on fuel rods during reactor operation. In previous work, we carried out first-principle-based thermodynamic modeling to describe the processes of formation and deposition of nickel ferrite particles in PWRs [20-24]. We combined results of density functional theory (DFT) calculations with experimental Gibbs free energies of formation to evaluate the surface energies of nickel ferrite as a function of temperature. To mimic the conditions of pressure, ionic concentrations, and $\mathrm{pH}$ in operating PWRs, we also incorporated elements of aqueous chemistry into the model $[20,21]$. Unexpectedly, it was found that several reconstructed nickel ferrite surfaces had negative formation energies, while the enthalpy of formation of the bulk material was positive. The combination of negative surface and positive bulk free 
energies predicts thermodynamically stable nickel ferrite nanoparticles in the PWR coolant.

In this paper, we use the first-principle informed thermodynamics method developed earlier $[20,21]$, to model the nucleation and formation of nickel ferrite nanoparticles from solvated ionic species under hydrothermal conditions.

\section{Theoretical Method}

Details of the DFT-informed thermodynamics scheme as well as details of the atomic structures used for the modeling of bulk and surfaces of nickel ferrite are described in our previous work $[20,21]$. Here, we only present a summary of the method. To determine the surface energies as a function of temperature, a set of temperature-dependent effective chemical potentials (ECP) are calculated based on the following system of linear equations:

$$
\begin{aligned}
\Delta_{f} G_{A_{x} B_{y} O_{z}}(T, P)= & E_{A_{x} B_{y} O_{z}}-x \mu_{A}^{0}(T)-y \mu_{B}^{0}(T) \\
& -\frac{z}{2} \mu_{O_{2}}^{0}(T)
\end{aligned}
$$

where the change in free energies, $\Delta_{f} G_{A_{x} B_{y} O_{z}}(T, P)$, are taken from the experiment $[25,26], E_{A_{x} B_{y} O_{z}}$ are the total DFT energies of various binary and ternary oxides, and $\mu_{i}^{0}$ are the ECPs that are determined by solving the system of linear equations (1) by the least squares method. Similar to the ECPs determined by equation (1), the chemical potentials for the solvated cations, $\mu_{M^{z+}, \text { aq }}^{0}$, are calculated using

$$
\begin{aligned}
\Delta_{f} G_{M^{z+}, \mathrm{aq}}^{0}(T, P)= & \mu_{M^{z+}, \mathrm{aq}}^{0}(T, P)-\mu_{M}^{0}(T) \\
& +\frac{z}{2} \mu_{\mathrm{H}_{2}}^{0}(T)-z \mu_{\mathrm{H}^{+}, \mathrm{aq}}^{0}(T) .
\end{aligned}
$$

The Gibbs energies of formation of the aqueous species, $\Delta_{f} G_{M^{z+}, \text { aq }}^{0}(T, P)$, used in equation (2) are taken from the SUPCRT database $[27,28]$. The chemical potential for the solvated proton is evaluated in terms of the $\mathrm{pH}$ value as

$$
\mu_{\mathrm{H}^{+}}(T)=\mu_{\mathrm{H}^{+}}^{0}\left(T_{r}\right)+R T \ln \left(10^{-\mathrm{pH}}\right) .
$$

Using the ECPs determined by equations (1) and (2), combined with DFT total energies calculated for the slab geometries, and assuming that the dissolved $\mathrm{Fe}$ and $\mathrm{Ni}$ are in $3+$ and $2+$ oxidation states, respectively, the temperaturedependent surface energies of nickel ferrite are calculated through

$$
\begin{aligned}
\gamma(T, P)= & \frac{1}{2 A}\left[\left(G_{\text {slab }}-\Gamma_{\mathrm{Fe}_{\mathrm{Fe}}} \mu_{\mathrm{Fe}^{3+}}-\Gamma_{\mathrm{Ni}_{\mathrm{Ni}}} \mu_{\mathrm{Ni}^{2+}}\right.\right. \\
& \left.-\Gamma_{\mathrm{NiFe}_{2} \mathrm{O}_{4}} g_{\mathrm{NiFe}_{2} \mathrm{O}_{4}}-n_{\mathrm{H}_{2}} \mu_{\mathrm{H}_{2} \mathrm{O}}\right) \\
& \left.-\left(\frac{3}{2} \Gamma_{\mathrm{Fe}}+\Gamma_{\mathrm{Ni}}\right)\left(2 \mu_{\mathrm{H}^{+}}-\mu_{\mathrm{H}_{2}}+\Delta_{f} G\left(H_{2, \mathrm{aq}}\right)\right)\right] .
\end{aligned}
$$

In equation (4), $G_{\text {slab }}$ and $g_{\mathrm{NiFe}_{2} \mathrm{O}_{4}}$ represent the DFT total energies of the surface slab and the bulk, $\mu_{i^{z+}}$ are the environment-dependent chemical potentials, and $\Gamma_{i}$ represent the surface excess quantities that are related to the number of atoms used in the reconstruction of the nonstoichiometric surfaces considered in the calculations. They are given by

$$
\begin{aligned}
\Gamma_{\mathrm{Fe}} & =n_{\mathrm{Fe}}-n_{\mathrm{O}_{2}}+\frac{n_{\mathrm{H}_{2}}}{2}, \\
\Gamma_{\mathrm{Ni}} & =n_{\mathrm{Ni}}-\frac{n_{\mathrm{O}_{2}}}{2}+\frac{n_{\mathrm{H}_{2}}}{4}, \\
\Gamma_{\mathrm{NiFe}_{2} \mathrm{O}_{4}} & =\frac{n_{\mathrm{O}_{2}}}{2}-\frac{n_{\mathrm{H}_{2}}}{4} .
\end{aligned}
$$

In the case of nonstoichiometric surfaces, the free energies are dependent on the environment via the chemical potentials. These are related to ECPs through the molal concentrations by the relation:

$$
\mu_{i^{++}}=\mu_{i^{+}}^{0}(T, P)+R T \ln \left[i^{z+}\right]
$$

The DFT calculations have been carried out using the VASP package $[29,30]$ with the GGA-PBE exchange correlation functional [31]. The on-site Coulomb interactions were added to the $d$-states of $\mathrm{Ni}$ and $\mathrm{Fe}$ in the Dudarev formulation [32], with the values of 6.0 and $4.5 \mathrm{eV}$, respectively.

In addition to characterizing nickel ferrite nanoparticles, the first-principle informed thermodynamics scheme, briefly described above, has been successfully used to investigate other processes that take place under operating PWRs, such as boron uptake by nickel ferrite [33] and formation of bonaccordite $\left(\mathrm{Ni}_{2} \mathrm{FeBO}_{5}\right)$ on nuclear fuel rods [34].

\section{Nucleation: Theory and Experiment}

Classical homogeneous nucleation theory gives the change in free energy $\Delta G^{T}$ as phase transformation proceeds as a sum of two terms. The first term is an interfacial energy per unit area, $\gamma$, times the area between the two phases. The second term is the difference in free energy of the two phases, $\Delta G$, times the volume of the transformed material. Therefore, the free energy change as the transformation progresses is given by

$$
\Delta G^{T}=(\text { surface area }) \cdot \gamma+(\text { volume }) \cdot \Delta G,
$$

where a combination of positive surface energy and a negative $\Delta G$ yields a free energy barrier for the nucleation process. In general, the magnitude of $\Delta G$ increases as the temperature is lowered below that of the phase transition, which produces both a smaller nucleation barrier and critical cluster radius. For direction-dependent $\gamma$ values, a Wulff construction can be used to determine appropriate volume and surface energies for a given nanoparticle size.

Nanocrystalline nickel ferrite has been synthesized through hydrothermal reaction and characterized in numerous experimental studies [11-17]. In hydrothermal processes, $\mathrm{Fe}$ is usually in a $3+$ oxidation state originating from 


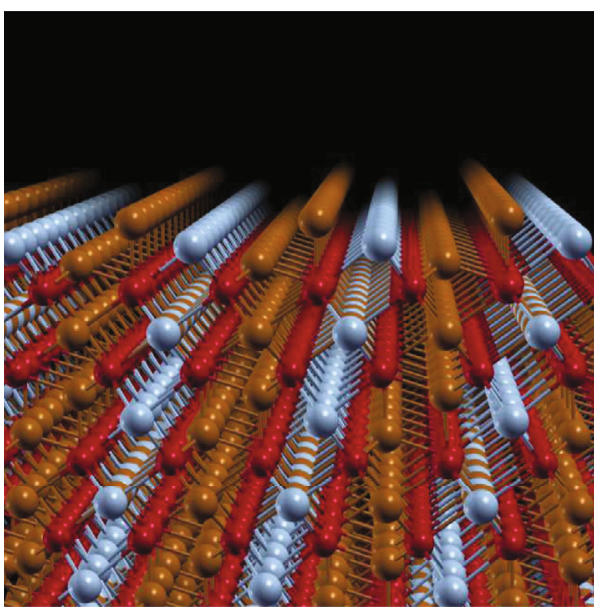

(a)

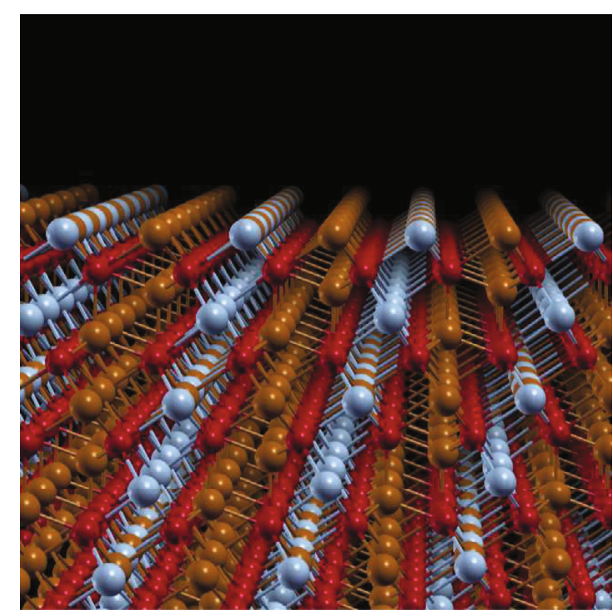

(b)

Figure 1: Slab models with the lowest (111) surface formation energies. The most stable surfaces expose (a) tetrahedral and (b) octahedral $\mathrm{Ni} / \mathrm{Fe}$ cations. The red balls represent $\mathrm{O}$ atoms, and the grey and brown are $\mathrm{Ni}$ and $\mathrm{Fe}$, respectively.

precursors such as $\mathrm{FeO}(\mathrm{OH}), \mathrm{Fe}(\mathrm{NO})_{3}$, and $\mathrm{FeCl}_{3}$ and the typical mole ratio of $\mathrm{Fe}: \mathrm{Ni}$ is close to $2: 1$. To simulate these conditions, the molal concentrations of $\mathrm{Fe}^{3+}$ and $\mathrm{Ni}^{2+}$ were set to $2 \times 10^{-21}$ and $1 \times 10^{-21} \mathrm{~mol} / \mathrm{kg}$. Furthermore, because higher alkalinity of the solution enhances the crystallization of nickel ferrite [11], the simulations were carried out for $\mathrm{pH}$ values ranging from 7 to 8 .

\section{Results and Discussions}

The surface free energies of nickel ferrite with 12 different terminations along the low index surfaces have been calculated. To explore the effect of the water chemisorption on surface stability, in addition to the bare surface configurations, the calculations were also carried out with $\mathrm{OH}$ groups attached to the surface metal ions and $\mathrm{H}$ attached to the surface oxygens. On several surface orientations, we also investigated the effect of $\mathrm{OH}$ and $\mathrm{H}$ adsorptions separately.

The energy of a stoichiometric surface, which is always positive, can be lowered by adsorbates or by surface reconstruction. Depending on the chemical potentials of the adsorbed species or the species participating in the surface reconstruction, the surface energies can become negative [35-37]. In our modeling, under hydrothermal conditions, several of the nickel ferrite surfaces have negative formation energies. This can be related to the reference chemical potentials of the aqueous species used in the calculations that depend on temperature, pressure, and $\mathrm{pH}$ value.

Under conditions of hydrothermal synthesis, the most stable surfaces of nickel ferrite are predicted to be along the (111) orientation. This is in agreement with earlier DFT simulations carried out on nickel ferrite surfaces [38]. Out of the six nonequivalent surface terminations examined along the (111) direction, the ones that expose the most metal cations are the most stable. As illustrated in Figures 1(a) and 1(b), these surfaces consist of metallic layers of tetrahedral and octahedral $\mathrm{Ni} / \mathrm{Fe}$ cations, respectively. Even though these surfaces create more broken bonds than other cuts along the
(111) direction, they are the most stable because the simulations were carried out under oxygen-poor conditions. Therefore, surfaces that expose more metal cations are more stable. The calculated energies associated with these two terminations are nearly the same: they differ by only $0.014 \mathrm{~J} / \mathrm{m}^{2}$, with the termination illustrated in Figure 1(a) being more stable. This difference in the surface energies is related to the DFT slab energies, and therefore, it is independent of temperature, $\mathrm{pH}$, or ion concentrations. The surfaces can be further stabilized through the adsorption of dissociated $\mathrm{H}_{2} \mathrm{O}$, by capping the exposed metal sites with $\mathrm{OH}$ groups and placing the $\mathrm{H}$ atoms above $\mathrm{O}$ atoms in the subsurface layer.

Plotted in Figure 2(a) are the free energies of formation of the most stable nickel ferrite surface (represented in Figure 1(a)) with and without $\mathrm{H}_{2} \mathrm{O}$ termination, as a function of temperature, for three different $\mathrm{pH}$ values. As mentioned earlier, the surfaces are stabilized by the adsorption of $\mathrm{H}_{2} \mathrm{O}$. At $300 \mathrm{~K}$, for instance, the presence of $\mathrm{H}_{2} \mathrm{O}$ lowers the surface formation energy by $\sim 7 \mathrm{~J} / \mathrm{m}^{2}$. However, as apparent in Figure 2(a), the exotermicity of the adsorption process decreases with temperature, such that around $600 \mathrm{~K}$ (not shown), the surface becomes denuded. This trend is consistent with the IR powder spectroscopy measurements that revealed water desorption from nickel ferrite surfaces at temperature above $400 \mathrm{~K}$ [11].

Using the conditions of temperature, $\mathrm{pH}$, and concentration of aqueous species specified above, the free energy for the formation of bulk nickel ferrite is evaluated through the reaction:

$$
\mathrm{Ni}^{2+}+2 \mathrm{Fe}^{3+}+4 \mathrm{H}_{2} \mathrm{O} \rightarrow \mathrm{NiFe}_{2} \mathrm{O}_{4}+\left(8 \mathrm{H}^{+}\right)_{\mathrm{aq}}
$$

As illustrated in Figure 2(b), the bulk free energy of formation, calculated by equation (8), decreases with temperature and $\mathrm{pH}$ but remains mostly positive for the entire range of $300-400 \mathrm{~K}$. As visible in Figures 2(a) and 2(b) as the values of temperature and $\mathrm{pH}$ increase, the surfaces become less stable while the bulk becomes more stable. 


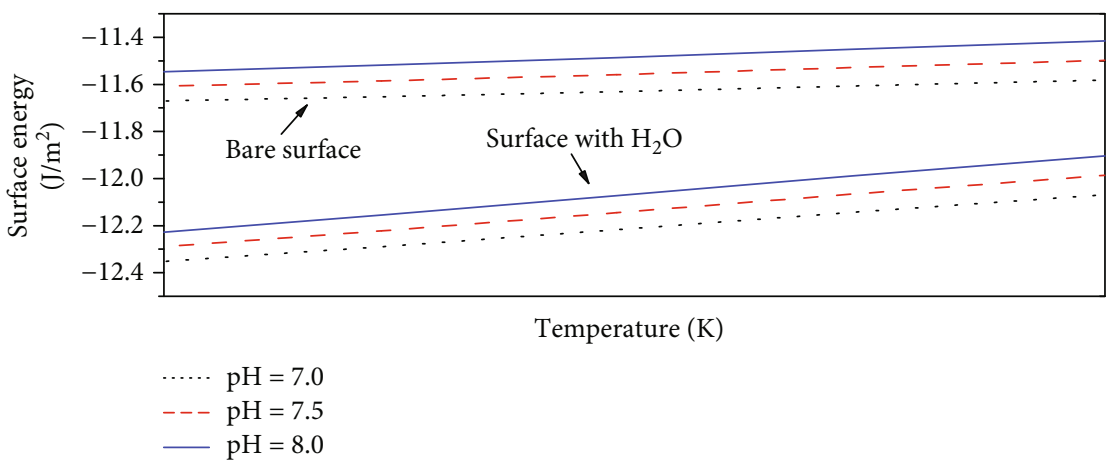

(a)

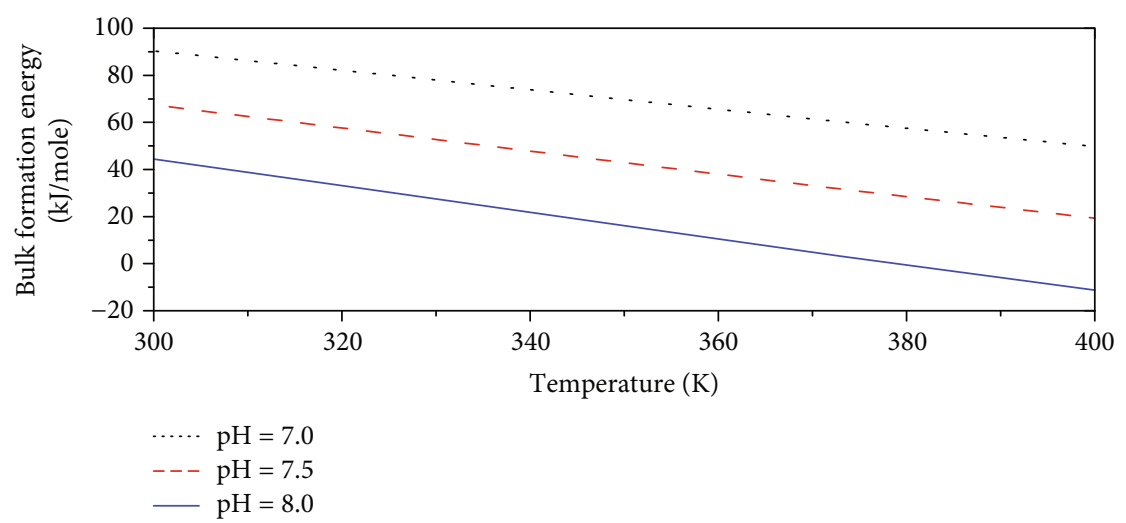

(b)

FIgURE 2: (a) Surface formation energies for the bare and hydroxylated nickel ferrite (111) surfaces as a function of temperature and $\mathrm{pH}$ value. The exotermicity of the $\mathrm{H}_{2} \mathrm{O}$ adsorption process decreases with temperature. (b) Free energy of formation for bulk nickel ferrite as a function of temperature and $\mathrm{pH}$. As the temperature and $\mathrm{pH}$ increase, the bulk becomes more stable.

At temperatures above $400 \mathrm{~K}$ and/or $\mathrm{pH}$ values above 8 , the free energy of formation of the bulk becomes negative (Figure 2(b)), causing the crystallization of bulk nickel ferrite.

A Wulff construction based on the surface energies described above predicts that nickel ferrite particles only expose their (111) surfaces, producing particles with octahedral morphology. This is consistent with the observation of the octahedral nickel ferrite particles ranging from 60 to $100 \mathrm{~nm}$ in size generated through hydrothermal reactions $[11,12]$.

To evaluate the thermodynamic stability of the nickel ferrite particles under hydrothermal conditions, the free energy associated with the formation of an octahedral particle is calculated as a function of size. This is done by adding the product of the negative (111) surface energy and the total surface area of the octahedral particle to the product of the positive formation energy of bulk nickel ferrite and the volume of the particle. The change in free energy for the formation of nickel ferrite particles as a function of particle size is plotted in Figure 3(a) for different temperatures. Interestingly, instead of the energy barriers expected from the classical nucleation theory, the calculated free energy curves in Figure 3 display energy wells, where the nickel ferrite clusters are predicted to be thermodynamically stable. This atypical behavior of the nucleation curve occurs because in our simulation, the surface energies of nickel ferrite are negative while the bulk formation energies are positive. As specified in the previous paragraph, the free energy for particle formation is the sum of a surface term and a volume term. Because the volume term varies more rapidly with size than the surface term, at small sizes, the surface term dominates and the free energy is negative. At larger particle sizes, the volume term takes over, and the free energy is dominated by the positive formation energy of bulk nickel ferrite. This is illustrated in Figure 3(a), where for temperatures ranging from 300 to $400 \mathrm{~K}$ and $\mathrm{pH}=7$, the free energy curves have minima corresponding to particle sizes of 30 to $60 \mathrm{~nm}$. As visible in Figure 3(b), the depth of the energy wells and the sizes of nickel ferrite particles associated with the wells depend sensitively on the $\mathrm{pH}$. As the alkalinity of the solution increases, the clusters become larger; for instance, at $350 \mathrm{~K}$ and $\mathrm{pH}=8$ , the side length of the nickel ferrite octahedron is predicted to be around $150 \mathrm{~nm}$. This trend as well as the predicted cluster sizes appears to be in good agreement with experimental results $[11,12]$.

\section{Conclusion}

This study combines results of first-principle DFT calculations with experimental data and elements of aqueous chemistry to evaluate the energetics of nickel ferrite synthesis in hydrothermal environments. Based on solid-liquid equilibrium conditions, the formation energies of the bare and 

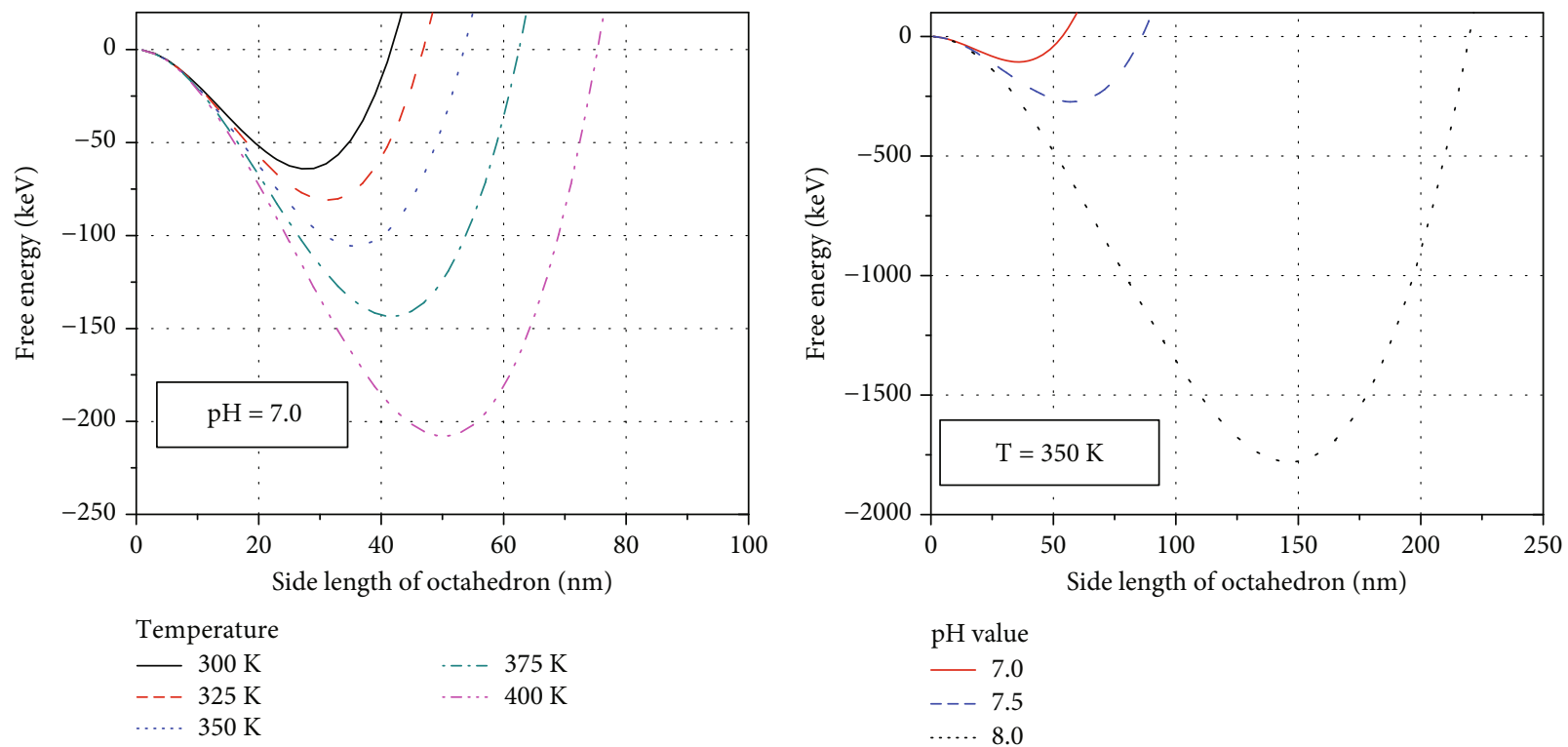

(a)

(b)

FIGURE 3: Free energies of formation of an octahedral nickel ferrite particle as a function of particle size for various (a) temperature and (b) $\mathrm{pH}$ values. The size of the nickel ferrite clusters associated with the free energy minima depends sensitively on temperature and $\mathrm{pH}$.

hydroxylated nickel ferrite surfaces have been calculated. The lowest formation energy belongs to the (111) surface formed by tetrahedral cation terminations. As a general trend, under conditions of temperature, ion concentration, and $\mathrm{pH}$ characteristic to hydrothermal reactions, surfaces that expose a larger number of metal cations are the most stable. These surfaces are further stabilized by the adsorption of dissociated water molecules. At temperatures above $400 \mathrm{~K}$, however, the water-induced stabilization decreases and the surfaces become denuded.

An important aspect of this study is related to the fact that the formation energy of the most stable (111) surface is negative, while the free energy of formation of the bulk material, under identical thermodynamic conditions, is positive. When creating a nickel ferrite particle, the energy cost associated with the formation of the bulk material is counterbalanced by the energy gained through the formation of the interface between the bulk and its aqueous surrounding. In terms of nucleation theory, the negative surface and positive bulk energies produce energy wells, with minima (and corresponding particle sizes) that depend sensitively on temperature, $\mathrm{pH}$, and ion concentration. The general trend regarding the phase stability and predicted nanoparticle size and morphology as a function of thermodynamic conditions agrees well with the experiment.

\section{Data Availability}

Data are available in thermochemical databases and previous publications cited in this article.

\section{Conflicts of Interest}

The authors declare that they have no conflicts of interest.

\section{Acknowledgments}

This research was supported by the Consortium for Advanced Simulation of Light Water Reactors (https://www .casl.gov), an Energy Innovation Hub (https://www.energy .gov/hubs) for Modeling and Simulation of Nuclear Reactors under U.S. Department of Energy Contract No. DE-AC0500OR22725.

\section{References}

[1] P. Moriarty, Reports on Progress in Physics, vol. 64, no. 3, pp. 297-381, 2001.

[2] H. Gleiter, "Tuning the electronic structure of solids by means of nanometer-sized microstructures," Scripta Materialia, vol. 44, no. 8-9, pp. 1161-1168, 2001.

[3] H. Gleiter, "Nanostructured materials: basic concepts and microstructure," Acta Materialia, vol. 48, no. 1, pp. 1-29, 2000.

[4] J. T. Hu, L. S. Li, W. D. Yang, L. Manna, L. W. Wang, and A. P. Alivisatos, "Linearly polarized emission from colloidal semiconductor quantum rods," Science, vol. 292, no. 5524, pp. 2060-2063, 2001.

[5] S. Komarneni, M. Tsuji, Y. Wada, and Y. Tamaura, "Nanophase ferrites for $\mathrm{CO}_{2}$ greenhouse gas decomposition," Journal of Materials Chemistry, vol. 7, no. 12, pp. 2339-2340, 1997.

[6] E. Hasmonay, J. Depeyrot, M. H. Sousa, F. A. Tourinho, J. C. Bacri, and R. Perzynski, "Optical properties of nickel ferrite ferrofluids," Journal of Magnetism and Magnetic Materials, vol. 201, no. 1-3, pp. 195-199, 1999.

[7] D. Wirtz and M. Fermigier, "One-dimensional patterns and wavelength selection in magnetic fluids," Physical Review Letters, vol. 72, no. 14, pp. 2294-2297, 1994.

[8] D. E. Speliotis, "Magnetic recording beyond the first 100 years," Journal of Magnetism and Magnetic Materials, vol. 193, no. 1-3, pp. 29-35, 1999. 
[9] K. Maaz, A. Mumtaz, S. K. Hasanain, and M. F. Bertino, "Temperature dependent coercivity and magnetization of nickel ferrite nanoparticles," Journal of Magnetism and Magnetic Materials, vol. 322, no. 15, pp. 2199-2202, 2010.

[10] K. Maaz, S. Karim, A. Mumtaz, S. K. Hasanain, J. Liu, and J. L. Duan, "Synthesis and magnetic characterization of nickel ferrite nanoparticles prepared by co-precipitation route," Journal of Magnetism and Magnetic Materials, vol. 321, no. 12, pp. 1838-1842, 2009.

[11] D. Chen, D. Chen, X. Jiao, Y. Zhao, and M. He, "Hydrothermal synthesis and characterization of octahedral nickel ferrite particles," Powder Technology, vol. 133, no. 1-3, pp. 247-250, 2003.

[12] Y. Cheng, Y. Zheng, Y. Wang, F. Bao, and Y. Qin, "Synthesis and magnetic properties of nickel ferrite nano-octahedra," Journal of Solid State Chemistry, vol. 178, no. 7, pp. 23942397, 2005.

[13] M. M. Bućko and K. Haberko, "Hydrothermal synthesis of nickel ferrite powders, their properties and sintering," Journal of the European Ceramic Society, vol. 27, no. 2-3, pp. 723$727,2007$.

[14] J. Huo and M. Wei, "Characterization and magnetic properties of nanocrystalline nickel ferrite synthesized by hydrothermal method," Materials Letters, vol. 63, no. 13-14, pp. 1183-1184, 2009.

[15] M. Salavati-Niasari, F. Davar, and T. Mahmoudi, “A simple route to synthesize nanocrystalline nickel ferrite $\left(\mathrm{NiFe}_{2} \mathrm{O}_{4}\right)$ in the presence of octanoic acid as a surfactant," Polyhedron, vol. 28, no. 8, pp. 1455-1458, 2009.

[16] K. Sue, M. Aoki, T. Sato et al., "Continuous hydrothermal synthesis of nickel ferrite nanoparticles using a central collisiontype micromixer: effects of temperature, residence time, metal salt molality, and $\mathrm{NaOH}$ addition on conversion, particle size, and crystal phase," Industrial \& Engineering Chemistry Research, vol. 50, no. 16, pp. 9625-9631, 2011.

[17] K. Nejati and R. Zabihi, "Preparation and magnetic properties of nano size nickel ferrite particles using hydrothermal method," Chemistry Central Journal, vol. 6, no. 1, p. 23, 2012.

[18] D. Chen, X. Jiao, and G. Cheng, "Hydrothermal synthesis of zinc oxide powders with different morphologies," Solid State Communications, vol. 113, no. 6, pp. 363-366, 1999.

[19] R. S. Sapieszko and E. Matijević, "Preparation of well-defined colloidal particles by thermal decomposition of metal chelates. I. Iron oxides," Journal of Colloid and Interface Science, vol. 74, no. 2, pp. 405-422, 1980.

[20] C. J. O’Brien, Z. Rák, and D. W. Brenner, "Free energies of (Co, $\mathrm{Fe}, \mathrm{Ni}, \mathrm{Zn}) \mathrm{Fe}_{2} \mathrm{O}_{4}$ spinels and oxides in water at high temperatures and pressure from density functional theory: results for stoichiometric $\mathrm{NiO}$ and $\mathrm{NiFe}_{2} \mathrm{O}_{4}$ surfaces," Journal of Physics: Condensed Matter, vol. 25, no. 44, article 445008, 2013.

[21] C. J. O’Brien, Z. Rák, and D. W. Brenner, “Calculated stability and structure of nickel ferrite crystal surfaces in hydrothermal environments," Journal of Physical Chemistry C, vol. 118, no. 10, pp. 5414-5423, 2014.

[22] C. J. O’Brien, Z. Rák, E. W. Bucholz, and D. W. Brenner, "First principles calculations predict stable $50 \mathrm{~nm}$ nickel ferrite particles in PWR coolant," Journal of Nuclear Materials, vol. 454, no. 1-3, pp. 77-80, 2014.

[23] D. W. Brenner, S. Lu, C. J. O’Brien, E. W. Bucholz, and Z. Rak, "A particle assembly/constrained expansion (PACE) model for the formation and structure of porous metal oxide deposits on nuclear fuel rods in pressurized light water reactors," Journal of Nuclear Materials, vol. 457, pp. 209-212, 2015.

[24] Z. Rak, C. J. O’Brien, D. W. Brenner, D. A. Andersson, and C. R. Stanek, JOM, vol. 68, no. 11, pp. 2912-2921, 2016.

[25] O. Kubaschewski, C. B. Alcock, and P. J. Spencer, Materials Thermochemistry, Pergamon Press, New York, NY, USA, 6th edition, 1993.

[26] M. W. Chase Jr, J. L. Curnutt, J. R. Downey Jr., R. A. McDonald, A. N. Syverud, and E. A. Valenzuela, "JANAF thermochemical tables, 1982 supplement," Journal of Physical and Chemical Reference Data, vol. 11, no. 3, pp. 695-940, 1982.

[27] T. Windman and E. Shock, "A web-based interactive version of SUPCRT92," Geochimica et Cosmochimica Acta, vol. 72, article A1027, 2008.

[28] J. W. Johnson, E. H. Oelkers, and H. C. Helgeson, “SUPCRT92: a software package for calculating the standard molal thermodynamic properties of minerals, gases, aqueous species, and reactions from 1 to 5000 bar and 0 to $1000^{\circ} \mathrm{C}$," Computers \& Geosciences, vol. 18, no. 7, pp. 899-947, 1992.

[29] G. Kresse and J. Furthmüller, "Efficient iterative schemes for $a b$ initio total-energy calculations using a plane-wave basis set," Physical Review B, vol. 54, no. 16, pp. 11169-11186, 1996.

[30] G. Kresse and J. Furthmüller, "Efficiency of ab-initio total energy calculations for metals and semiconductors using a plane-wave basis set," Computational Materials Science, vol. 6, no. 1, pp. 15-50, 1996.

[31] J. P. Perdew, K. Burke, and M. Ernzerhof, "Generalized gradient approximation made simple," Physical Review Letters, vol. 77, no. 18, pp. 3865-3868, 1996.

[32] S. L. Dudarev, G. A. Botton, S. Y. Savrasov, C. J. Humphreys, and A. P. Sutton, "Electron-energy-loss spectra and the structural stability of nickel oxide: an LSDA+U study," Physical Review B, vol. 57, no. 3, pp. 1505-1509, 1998.

[33] Z. Rák, E. W. Bucholz, and D. W. Brenner, "Defect formation in aqueous environment: theoretical assessment of boron incorporation in nickel ferrite under conditions of an operating pressurized-water nuclear reactor (PWR)," Journal of Nuclear Materials, vol. 461, pp. 350-356, 2015.

[34] Z. Rak, C. J. O'Brien, D. Shin, A. D. Andersson, C. R. Stanek, and D. W. Brenner, "Theoretical assessment of bonaccordite formation in pressurized water reactors," Journal of Nuclear Materials, vol. 474, pp. 62-64, 2016.

[35] Z. Lodziana, N. Y. Topsoe, and J. K. Norskov, "A negative surface energy for alumina," Nature Materials, vol. 3, no. 5, pp. 289-293, 2004.

[36] Z. Rak, R. C. Ewing, and U. Becker, "Hydroxylation-induced surface stability of $\mathrm{AnO}_{2}(\mathrm{An}=\mathrm{U}, \mathrm{Np}, \mathrm{Pu})$ from first-principles," Surface Science, vol. 608, pp. 180-187, 2013.

[37] Y. J. Siao, P. L. Liu, and Y. T. Wu, "Ab initio study of atomic hydrogen on $\mathrm{ZnO}$ surfaces," Applied Physics Express, vol. 4, no. 12, article 125601, 2011.

[38] P. V. Kumar, M. P. Short, S. Yip, B. Yildiz, and J. C. Grossman, "High surface reactivity and water adsorption on $\mathrm{NiFe}_{2} \mathrm{O}_{4}$ (111) surfaces," Journal of Physical Chemistry C, vol. 117, no. 11, pp. 5678-5683, 2013. 


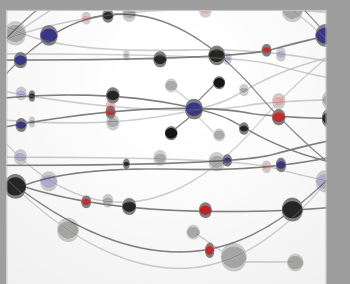

The Scientific World Journal
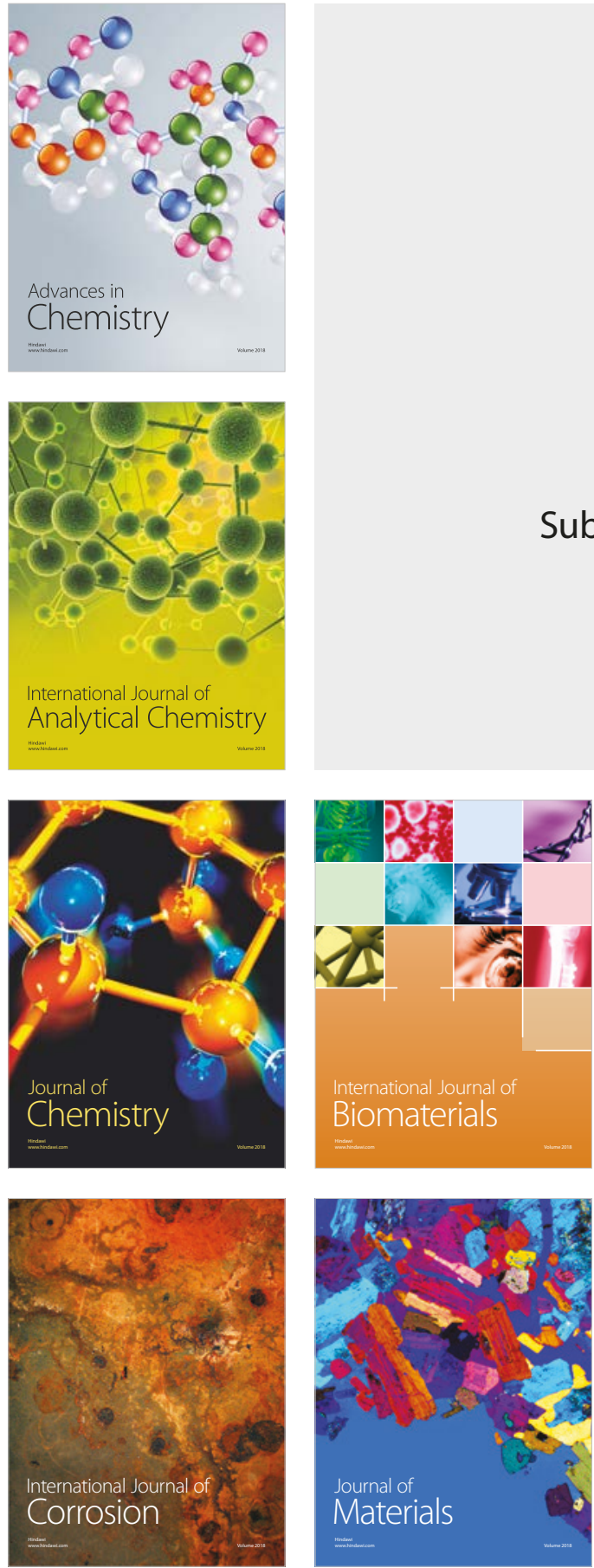

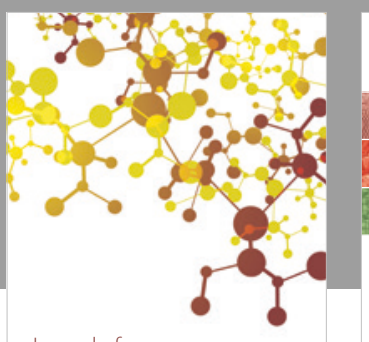

Journal of

Applied Chemistry
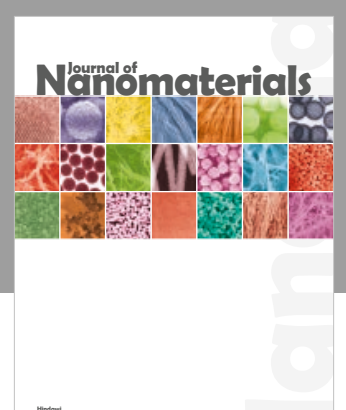

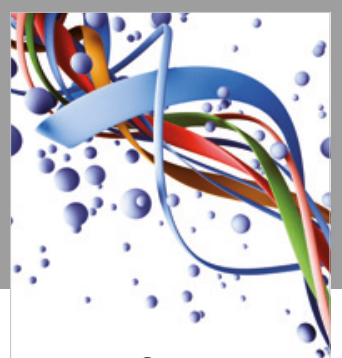

Scientifica

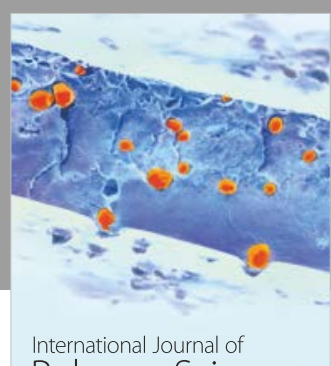

Polymer Science

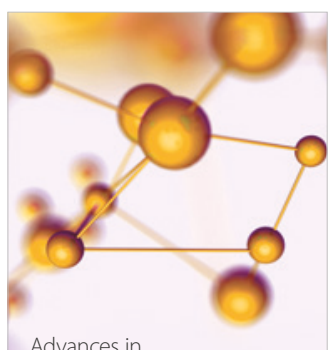

Physical Chemistry
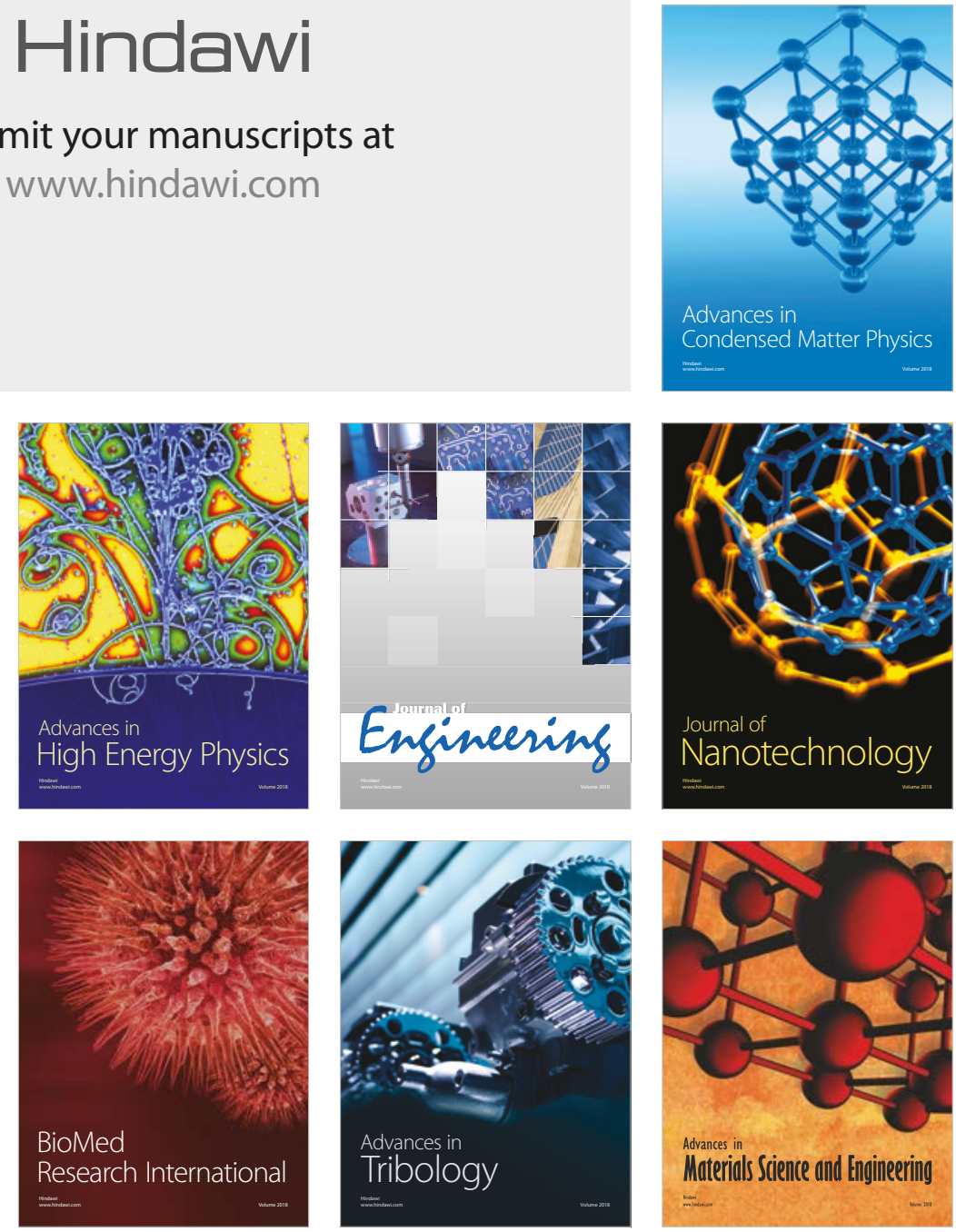